\title{
Unprecedented coral bleaching across the Marianas Archipelago
}
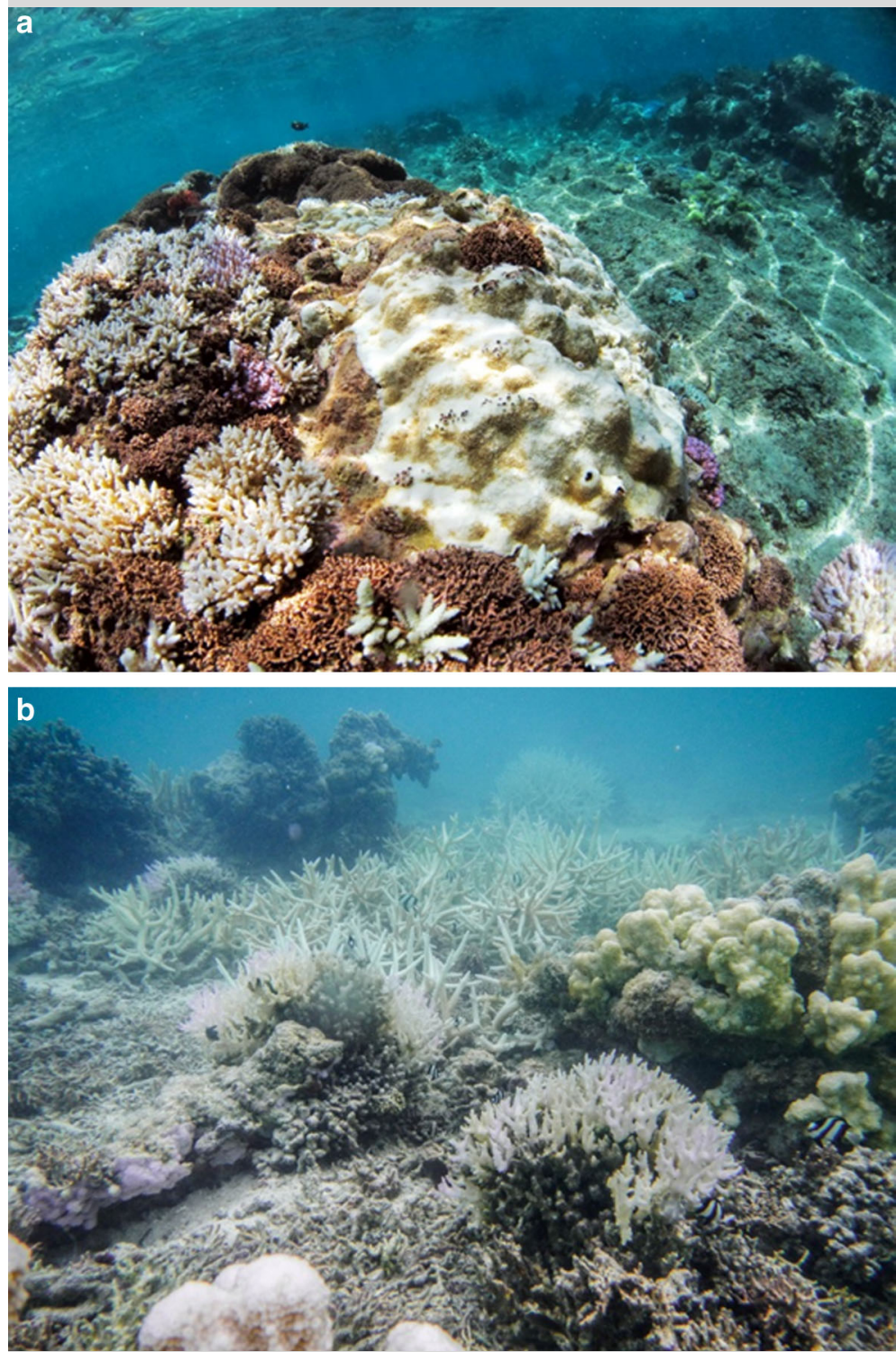

Fig. 1 a A reefscape near Fadian Point, Guam (photo by P. Houk), and b a bleached staghorn Acropora thicket in Saipan Lagoon, CNMI (photo by S. Johnson)

T. Reynolds $(\bowtie)$ D. Burdick · P. Houk · L. Raymundo

University of Guam Marine Laboratory, Mangilao, GU 96923, USA

e-mail: traviscreynolds@gmail.com

S. Johnson

CNMI Division of Environmental Quality, PO Box 501304, Saipan, MP 96950, USA
In 1998, many reefs around the world experienced severe, widespread bleaching and mortality coinciding with anomalously high sea surface temperatures (SSTs). The Marianas Archipelago was an exception in the Indo-Pacific region in which SSTs remained within normal ranges during this period (Rayner et al. 2006). Prior to 1998 and during non-El Niño years, surveys across the Marianas reported mild to moderate bleaching ( $68 \%$ of taxa showed signs of bleaching in 1994; Paulay and Benayahu 1999). Since 1998, cumulative evidence from published and anecdotal reports suggests that Marianas reefs have not experienced extensive impacts from coral bleaching over the past two decades (Burdick et al. 2008; P. Houk pers. obs).

We report the first known severe, widespread bleaching and mortality event across the three largest islands in the lower Marianas Archipelago: Guam, Rota, and Saipan (Fig. 1). In 2013, $85 \%$ of taxa on nearshore reefs showed signs of bleaching. The 2013 bleaching event coincided with local offshore SSTs exceeding the maximum monthly mean by $0.5-1.6^{\circ} \mathrm{C}$, from July 2013 through October 2013, ending after Typhoon Francisco formed southwest of Guam. The National Weather Service monitoring recorded wind speeds $\sim 2 \mathrm{~m} \mathrm{~s}^{-1}$ slower than monthly averages in July and August. This produced sustained, low wave energy along the windward (eastern) side of the islands simultaneously with elevated SSTs. As global SSTs continue to increase, reefs worldwide will remain vulnerable to bleaching events. Understanding differential responses among taxa and reefs to better predict bleachinginduced changes is a critical first step to managing for reef resilience and promoting recovery from such events.

Acknowledgments J. Gault, J. Iguel, R. Okano, and J. Miller for field support.

References

Burdick D, Brown V, Asher J, Caballes C, Gawel M, Goldman L, Hall A, Kenyon J, Leberer T, Lundblad E, McIlwain J, Miller J, Minton D, Nadon M, Pioppi N, Raymundo L, Richards B, Schroeder R, Schupp P, Smith E, Zglickzynski B (2008) Status of the coral reef ecosystems of Guam. Bureau of Statistics and Plans, Guam Coastal Management Program

Paulay G, Benayahu Y (1999) Patterns and consequences of coral bleaching in Micronesia (Majuro and Guam) in 1992-1994. Micronesica 32:109-124

Rayner NA, Brohan P, Parker DE, Folland CK, Kennedy JJ, Vanicek M, Ansell T, Tett SFB (2006) Improved analyses of changes and uncertainties in sea surface temperature measured in situ since the mid-nineteenth century: the HadSST2 data set. J Clim 19:446-469 